\title{
OS TRABALHADORES DO NORTE DE MINAS GERAIS: ENTRE O “DESENVOLVIMENTO” E O “PROGRESSO”
}

\section{Valéria de Jesus Leite*}

RESUMO: Neste artigo, analisamos a organização dos trabalhadores em Montes Claros e Norte de Minas Gerais, suas demandas e suas lutas, entre as décadas de 1970 e 1980. Especificamente, trataremos a respeito de como se deu o processo de modernização econômica na cidade de Montes Claros e de como esse processo, efetivado a partir da década de 1960, afetou a vida dos trabalhadores, tanto nesta cidade como na referida região. É importante ressaltar que, quando tratamos do processo de modernização das estruturas econômicas de Montes Claros, não podemos nos restringir somente aos seus limites geográficos, pois estaremos também fazendo uma análise da região e do país. A dinâmica experimentada durante o período em questão nos mostra que as transformações pelas quais passou essa cidade na segunda metade do século passado afetaram a região como um todo, do mesmo modo que, por sua vez, as transformações ocorridas na região influíram em Montes Claros.

PALAVRAS-CHAVE: Trabalhadores. Movimentos sociais. Norte de Minas.

ABSTRACT: In this article, we analyzed the workers' organization in Montes Claros and North of Minas Gerais, their demands and their struggles, between the 1970s and 1980s. Specifically, we will deal with the modernization of the economic process in Montes Claros and how this process effective since the 1960s, affected

\footnotetext{
* Doutora em História Social pela Universidade Federal de Uberlândia.
} Professora da rede pública de ensino de Minas Gerais 
the workers' life, both in this city and its region. It is important to emphasize that when we deal with the modernization process of the economic structures of Montes Claros, we can not restrict ourselves to its geographical limits, we will also be analyzing the region and the country. The dynamics experienced during the period in question shows the transformations that this city passed in the second half of the last century affected the region as a whole, in the same way that the transformations that took place in the region has influenced in Montes Claros.

KEYWORDS: Workers. Social movements. North of Minas Gerais.

\section{Buscando o desenvolvimento e o progresso}

A partir da segunda metade do século XX, o Brasil, como um todo, passou por profundas transformações de caráter político, econômico e social.

Em 1959, foi criada a Superintendência de Desenvolvimento do Nordeste (Sudene). A Sudene foi um projeto do governo federal, idealizado por Celso Furtado, que pretendia alavancar o crescimento do país, corrigindo as disparidades regionais, sobretudo dos estados na região que hoje conhecemos como Nordeste, em relação ao Centro-Sul. Celebrada por muitos e questionada por tantos outros, a Sudene, enquanto incentivadora de vários projetos, esteve presente no processo de modernização econômica do Norte de Minas a partir de 1965, momento em que a industrialização em Minas Gerais começou a se consolidar. ${ }^{1}$

Quando a Sudene foi criada, as lideranças políticas do Norte de Minas já estavam em sintonia e apresentavam capacidade de mobilização, conforme foi constatado por Pereira (2007), sendo

1 Sobre críticas ao modelo Sudene de desenvolvimento, ver: OLIVEIRA, Francisco de. Elegia para uma re(li)gião. Sudene, Nordeste. Planejamento e conflitos de classe. 5. ed. Rio de Janeiro: Paz e Terra, 1987. 
que uma de suas mais importantes conquistas foi a inclusão do Norte de Minas na área de abrangência da Sudene. Com isso, o Norte de Minas Gerais, a partir de 1965, passou a fazer parte de duas dinâmicas desenvolvimentistas maiores, a mineira e a nordestina, sendo que esta última tinha sua pauta direcionada pela Sudene e se baseava em políticas de combate à seca e de geração de emprego. Por isso, entender a dinâmica do Nordeste é importante para entender também a dinâmica do Norte de Minas, já que as transformações aqui ocorridas só foram possíveis por meio dos investimentos da Sudene.

Todavia, as políticas públicas do governo federal para promover o desenvolvimento do Nordeste tiveram início muito antes da Sudene. Segundo informa Rodrigues (1998, p. 17-29), as ações governamentais buscando promover o desenvolvimento do Nordeste aconteceram desde o fim da Segunda Guerra Mundial e envolviam o aproveitamento dos recursos da bacia do Rio São Francisco. Até a criação da Sudene, em 1959, o governo federal já havia destinado inúmeros recursos para projetos e ações, principalmente com relação às questões hídricas, como a construção de barragens.

Nesse sentido, foi criada, em 1945, a Companhia Hidrelétrica do São Francisco (CHESF) e, em 1946, a Comissão do Vale do São Francisco (CVSF), inspirada no modelo norte-americano de valorização econômica do Vale do Rio Tennessee. A CVSF foi efetivamente criada em 1948 e estava vinculada diretamente à Presidência da República. Seu objetivo foi elaborar e executar um plano geral para o aproveitamento do Vale do São Francisco, considerando todo o potencial hidrelétrico do Vale, desenvolvendo a agricultura, a irrigação, a indústria, as comunicações, a educação e a saúde, além de coordenar as desapropriações de terra e o assentamento de agricultores (RODRIGUES, 1998, p. 17-29). Esse foi um plano de desenvolvimento com ações complexas que requereu um extenso conjunto de atividades e responsabilidades.

Entre 1964 e 1967, o governo estadunidense prestou assistência técnica à Comissão do Vale do São Francisco, em convênio que envolvia também a Sudene, a CHESF e a United 
States Agency International Development (USAID). A intenção foi fazer um estudo mais elaborado dos recursos hídricos e dos solos do Vale do São Francisco com o objetivo de desenvolver a irrigação. Os resultados apresentados apontaram uma capacidade de três milhões de hectares de terras irrigáveis e $12.500 \mathrm{MW}$ de potencial hidroelétrico, assim como a necessidade de reestruturar a Comissão do Vale do São Francisco. Seguindo tais recomendações, em 1967 o governo extinguiu essa instituição e criou a Superintendência para o Desenvolvimento do Vale do São Francisco (Suvale). Esta, no entanto, não contava com a mesma autonomia da CVSF e seus programas estavam atrelados à Sudene (RODRIGUES, 1998, p. 17-29).

Já em 1972, o governo brasileiro extinguiu a Superintendência para o Desenvolvimento do Vale do São Francisco (Suvale) e criou, em 1974, a Companhia de Desenvolvimento do Vale do São Francisco (Codevasf). A Codevasf tinha como objetivo aproveitar os recursos hídricos e do solo do Rio São Francisco para a agricultura, pecuária e indústria, diretamente ou por meio de organismos públicos e privados (RODRIGUES, 1998, p. 17-29). Foi com base neste planejamento e racionalidade, idealizados e colocados em prática por agentes do Estado, que a classe dirigente do Norte de Minas passou a viabilizar seus interesses, os quais seriam defendidos e difundidos como interesses de todos os nortemineiros.

É interessante dizer que o Norte de Minas foi incluído na área de abrangência da Sudene em 1965. A partir desse ano, foi inaugurado, em Montes Claros, cidade considerada polo regional, um escritório do órgão com o objetivo de facilitar as relações entre as lideranças regionais e sua cúpula. Nesse mesmo ano, 1965, foi completada a rede de transmissão do sistema de abastecimento de energia da usina hidrelétrica de Três Marias e inaugurado o Frigorífico Frigonorte, antiga reivindicação dos pecuaristas locais, também em Montes Claros. Em 1976, a Associação Comercial e Industrial de Montes Claros ( $\mathrm{ACl}$ ) conduziu importantes investimentos para a cidade, dentre os quais a criação da Escola Técnica, que tinha como finalidade formar e qualificar mão de obra para as indústrias incentivadas pela Sudene. 
Portanto, em conformidade com o ideal desenvolvimentista, as políticas para o desenvolvimento regional basearam-se na industrialização incentivada nas cidades, com destaque para Montes Claros e Pirapora, e no incremento das relações produtivas no campo. É importante lembrar que os projetos agropecuários (como a pecuária de corte e o reflorestamento) foram apoiados pelo Instituto Brasileiro de Desenvolvimento Florestal, enquanto os projetos públicos de agricultura irrigada (Gorutuba, Jaíba, Pirapora e Jequitaí) ficaram a cargo da Codevasf e da Ruralminas. Assim, a Codevasf, articulada à Sudene e à Ruralminas, coordenou o desenvolvimento econômico na bacia do São Francisco (RODRIGUES, 1998, p. 17-29). As transformações, fossem no campo ou nas cidades, tiveram como base e aconteceram atreladas a uma dinâmica maior, isto é, à do capitalismo brasileiro, principalmente às indústrias do centro-sul, sempre em conformidade com a lógica capitalista mundial. À frente desse processo estava a burguesia local associada a agentes do poder público, em âmbito estadual e federal, por meio das ações de órgãos como a Sudene, a Ruralminas e a Codevasf.

A imagem de Montes Claros como centro polarizador regional foi sendo construída e, com o tempo, adquiriu consistência como tal, tornando a cidade a "princesa do norte". Já nesse período, a cidade começava a crescer e, consequentemente, a atrair pessoas buscando melhores condições de vida, o que elevou o número de habitantes. Com o crescimento demográfico acelerado, sobretudo a partir da década de 1970, período em que a indústria, sob incentivo, foi responsável por $45,63 \%$ do emprego industrial no município, esse foi o momento em que, segundo Oliveira (2000), Montes Claros e o Norte de Minas começaram a sentir os resultados positivos das políticas de promoção industrial, com uma taxa de emprego de $85,1 \%$ para o ano de $1977 .{ }^{2}$

As transformações nas relações de trabalho no campo

2 Os efeitos positivos da modernização econômica foram sentidos de forma mais acentuada em Montes Claros e cidades como Pirapora, Janaúba, Januária. 
acabaram por reestruturar as antigas formas de produção, a exemplo das parcerias e/ou agregações, e isso contribuiu para o esvaziamento do campo e o crescimento desordenado das cidades, principalmente Montes Claros. Cabe ressaltar que esse modelo de desenvolvimento que modernizou a economia não foi capaz de promover um desenvolvimento social e humano e, por isso mesmo, foi o tempo todo tensionado pela classe trabalhadora, por meio de associações classistas ou pela atuação das pastorais. Em especial, a atuação das Comunidades Eclesiais de Base, nesse processo, foi extremamente significativa. A Pastoral da Terra e a Pastoral Operária participaram da organização dos trabalhadores, da constituição dos sindicatos e da formação de lideranças, a exemplo do que aconteceu no restante do país. Podese dizer, portanto, que os trabalhadores, ancorados nas pastorais sociais da Igreja Católica, tiveram condições de questionar e causar tensão no projeto da classe dirigente local, nas cidades, reivindicando infraestrutura nos bairros (água, luz, saneamento, escolas, pavimentação de ruas, limpeza pública, postos de saúde, hospitais) e na zona rural, lutando pelo cumprimento dos direitos trabalhistas e na luta pela terra. É sobre os trabalhadores e suas lutas que falaremos em seguida.

\section{Os trabalhadores rurais assalariados e o "progresso que traz cativeiro"}

Já foi dito que o projeto de desenvolvimento para o Norte de Minas Gerais foi parte de uma dinâmica maior, cujas transformações se fizeram sentir, principalmente, a partir da década de 1960. A paisagem rural da região foi remodelada pelas extensas plantações de eucaliptos. Os perímetros irrigados para cultivo de frutas foram construídos entre as cidades de Jaíba e Matias Cardoso, entre Janaúba e Nova Porteirinha e em Pirapora. No caso, os projetos Jaíba, Gorutuba, Lagoa Grande e Pirapora, respectivamente. A implantação desses projetos de irrigação só foi possível com a desapropriação de centenas de famílias, tarefa que ficou a cargo da Codevasf, da Ruralminas e do Departamento 
Nacional de Obras Contra as Secas (DNOCS). Portanto, para que o desenvolvimento e o progresso se efetivassem no Norte de Minas, era preciso retirar os trabalhadores de suas terras.

Os primeiros passos do progresso na região se deram com a chegada das reflorestadoras, na década de 1970. A ação das reflorestadoras contribuiu para acirrar os conflitos no campo, pois a tensão envolvia os pequenos sitiantes, posseiros, fazendeiros e as empresas de reflorestamento. Para os trabalhadores rurais assalariados, a violência acontecia através do não cumprimento da legislação trabalhista e do total desrespeito aos direitos humanos. Em sua página na internet, a Pastoral da Terra apresenta alguns números da violência experimentada pelo trabalhador rural na década de 1980. Abaixo, o Quadro 1, com parte dos dados retirados do site da Pastoral da Terra para o Norte de Minas:

Quadro 1 - Acidentes com trabalhadores rurais assalariados e boias-frias em 1985 (Norte de Minas).

\begin{tabular}{|c|c|c|c|c|c|}
\hline Data & Trabalhador & Cidade & Idade & Empregador & Acidente \\
\hline $25 / 01$ & Hamilton de O. Neto & Itacambira & 17 & Plantar & $\begin{array}{l}\text { Morto em balsa } \\
\text { sem segurança. }\end{array}$ \\
\hline $25 / 01$ & Miguel José dos Santos & Itacambira & 27 & Plantar & $\begin{array}{l}\text { Morto em balsa } \\
\text { sem segurança. }\end{array}$ \\
\hline $27 / 07$ & $\begin{array}{l}\text { Dois trabalhadores } \\
\text { mortos e não identifi- } \\
\text { cados }\end{array}$ & Varzelândia & & & Capotamento. \\
\hline $04 / 09$ & $\begin{array}{l}\text { Quatro boias-frias mor- } \\
\text { tos }\end{array}$ & Espinosa & & & $\begin{array}{l}\text { Caminhão sem } \\
\text { freio. }\end{array}$ \\
\hline
\end{tabular}

Fonte: Comissão Pastoral da Terra, 1985.

Disponível em: <http://www.cptnacional.org.br/index.php/downloads/finish/43-conflitos-no-campo-brasil-publicacao/ 266-conflitos-no-campo-brasil-1985>. Acesso em: 10 jan. 2014.

Entre janeiro e setembro de 1985, foram oito trabalhadores mortos devido à precariedade das condições de trabalho das empresas de reflorestamento. A falta de segurança e o desrespeito 
aos direitos trabalhistas eram sempre noticiados nos meios de comunicação alternativos ou populares, principalmente nos boletins produzidos pelas Comunidades Eclesiais de Base, pela Comissão Pastoral da Terra e pela Pastoral Operária. Os boletins Integração e Pelejando eram periódicos editados pela Igreja Católica, por meio das Dioceses, em nível regional e estadual, respectivamente. Esses boletins tinham grande circulação entre as Comunidades Eclesiais de Base, os sindicatos e as associações urbanas e rurais, bem como entre os parceiros da Igreja, naquele período. Os boletins eram feitos com a colaboração dos membros das comunidades que enviavam notícias sobre os conflitos de terra, assassinatos de trabalhadores, desrespeitos aos direitos trabalhistas e humanos, fundação de associações e sindicatos. Portanto, os boletins cumpriam o objetivo de informar e ajudar na formação de um trabalhador mais crítico a respeito da sociedade.

Especificamente no Jornal Integração, editado na Diocese de Montes Claros, na seção CPT Denuncia, encontramos uma matéria informando sobre as vítimas diárias das Reflorestadoras no Norte de Minas. As mortes de Hamilton e Miguel José dos Santos, constantes do Quadro 1 acima, aconteceram no Rio Congonhas quando eles faziam o transporte de mudas de eucalipto em uma balsa improvisada com tambores e tábuas puxadas por duas cordas de nylon. A embarcação não resistiu à força das águas. Há também dois trabalhadores não identificados, moradores da cidade de Varzelândia, mortos em um capotamento. Eram dois jovens, Geraldo e Agostinho, este último era líder comunitário e do culto dominical (INTEGRAÇÃO, 1985).

O avanço do reflorestamento aconteceu expulsando os pequenos sitiantes e posseiros. Nesse ambiente, os trabalhadores rurais que foram empregados pelas reflorestadoras se viram obrigados a conviver com uma situação constante de riscos, pois estavam expostos aos venenos que eram levados junto com eles nos caminhões e trabalhavam muito mais que as oito horas estabelecidas pela lei. Além disso, esses trabalhadores não recebiam as horas extras e não tinham assistência médica; tampouco recebiam os dias em que se ausentavam quando 
estavam doentes. Muitas vezes, moravam em acampamentos feitos de plástico, com água velha e quente para beber (CPT, 1984, p. 16-25). Muitos desses trabalhadores não tinham a carteira assinada e corriam o risco de perder a vida nos caminhões que os transportavam. No quadro apresentado acima, constam seis trabalhadores mortos em acidentes com caminhões que os transportavam.

Nessas circunstâncias, a organização dos trabalhadores em sindicatos possibilitou, mesmo que por pouco tempo, inúmeras mobilizações que buscavam melhores condições de trabalho, reconhecimento social e respeito. A importância das pastorais sociais nesse processo, cabe ressaltar, foi fundamental. Em especial, a Pastoral da Terra e a Pastoral Operária subsidiaram a organização dos trabalhadores. Elas significavam muito mais que uma ligação entre Igreja e seus fiéis, pois eram uma ponta de esperança em meio às agruras da vida. Ademais, ofereciam um suporte extremamente necessário à medida que a luta se tornava maior e mais abrangente. ${ }^{3}$

Dentre os materiais de apoio elaborados pela CPT em maio de 1984, em conjunto com os sindicatos rurais, está um pequeno livro cujo título é "História das lutas dos trabalhadores rurais: greve no Paraíso". Este caderno foi feito para debater a greve dos trabalhadores da Florestaminas (reflorestadora presente na região), ocorrida entre 30 de maio e 12 de junho de 1983 e organizada pelo Sindicato dos Trabalhadores Rurais de São João do Paraíso em parceria com os trabalhadores. É um material interessante e contém um significado importante para a luta dos trabalhadores, pois nele está registrada uma parte da história vivida pelos trabalhadores do reflorestamento naquela cidade, sob sua própria perspectiva.

O caderno foi organizado em nove tópicos a serem debatidos em reuniões ou encontros das Comunidades Eclesiais de Base. Nesses tópicos, foram abordados os conflitos e a exploração

3 Para maiores informações sobre a constituição dos sindicatos na região, ver: Augusto, 2011. 
a que os trabalhadores do reflorestamento eram diariamente submetidos, desde a chegada das reflorestadoras e a consequente mudança nas relações de produção. O texto denuncia o ideal de progresso que aprisiona o pequeno trabalhador ao invés de libertálo. Aprisiona porque promove a perda da terra do pequeno sitiante para as empresas que aumentavam suas cercas e iludiam pessoas simples com promessas de bons salários e progresso para todos. Além de relatar a movimentação que antecedeu à greve, o texto também discute os problemas e os obstáculos enfrentados pelos trabalhadores em sua organização, suas pequenas conquistas até a decisão de greve pela assembleia geral. Percebe-se que, ao rememorar esse passado, o objetivo é conhecê-lo e apresentá-lo a outros. Assim, usando o passado como arma para transformar o presente, torna-se possível redimi-lo (LOWY, 2005). Significa, portanto, que ele não foi em vão.

Segundo informa a CPT, o intuito foi registrar a história para que outros trabalhadores a conhecessem e para que, em alguma medida, esses registros pudessem contribuir na organização de outros trabalhadores (CPT, 1984).

Nesse processo de luta, a organização dos trabalhadores era sempre desmantelada pelos representantes das empresas de reflorestamento. Entretanto, mesmo nas situações adversas, os trabalhadores conseguiam manter seus sindicatos e continuavam promovendo encontros. A importância da Comissão Pastoral da Terra pode ser avaliada também quanto a momentos em que, por meio dos seus jornais, dava destaque aos encontros e às pautas discutidas, divulgando a situação precária dos trabalhadores, assim como os principais assuntos debatidos nas reuniões, como a situação dos trabalhadores que lidavam com o cultivo do eucalipto, tanto no plantio como na produção do carvão. Ambas as situações eram precárias e sem segurança, tendo em vista que os trabalhadores não conseguiam suportar o serviço por mais de seis anos (PELEJANDO, 1984).

As reflorestadoras eram constantemente acusadas de não cumprirem a legislação trabalhista, seja em Grão Mogol, Rubelita, Rio Pardo de Minas, São João do Paraíso, Taiobeiras ou qualquer 
outra cidade. E, nesse ambiente, a situação de exploração agia como um combustível na organização da luta contra as arbitrariedades.

A situação de exploração dos trabalhadores não ficou restrita às empresas de reflorestamento. Uma matéria veiculada pela Revista Montes Claros em Foco, em novembro de 1979, discutia a aplicação da legislação trabalhista na zona rural da região. O título foi "O problema trabalhista: ameaça ou direito?" Consta na nota que "já houve até crime de morte, quando um fazendeiro matou seu empregado que queria receber pela terceira vez." (MONTES CLAROS EM FOCO, 1979, p. 56).

O caso foi apresentado e discutido como um fato cotidiano. Isso significa que foi, ao mesmo tempo, uma maneira de legitimar a fala dos fazendeiros e desqualificar as demandas dos trabalhadores. Para uma parcela considerável dos criadores de gado, a crise no campo teve uma causa muito distante do que fora experimentado pelos trabalhadores. Segundo a reportagem, fazendeiros da região que, anteriormente mantinham em suas propriedades vinte ou trinta famílias, naquela data (1979), mantinham uma ou duas. Isso, segundo os fazendeiros, acontecia porque a Legislação Trabalhista Rural era um "fantasma que ronda o campo", pois permitia aos trabalhadores rurais reclamar seus direitos trabalhistas em qualquer época, caso se sentissem lesados pelo patrão.

Segundo a matéria, Edilson Brandão, pecuarista, agricultor e liderança em Janaúba, disse que "são estes direitos, infindáveis no tempo, que estão causando o esvaziamento no campo". Ressaltou, inclusive, que "é mais seguro não ter o empregado" (MONTES CLAROS EM FOCO, 1979, p. 56), visto que a qualquer momento o fazendeiro poderia enfrentar causas trabalhistas que não teria como quitar. Opinião que foi compartilhada pelo advogado Eustáquio Cruzoé, de família tradicional na cidade. Nessa perspectiva, o esvaziamento no campo havia tido como causa a má conduta de trabalhadores rurais, mesquinhos e gananciosos, que usaram de ardil para enganar seus patrões e obter ganhos na justiça do trabalho. 
Esse é a tese sobre a qual foi construída a matéria pela revista Montes Claros em Foco. Nas seis páginas que discutem o tema, as imagens do homem do campo - seja à frente de sua casa feita de adobe ou com um saco nas costas caminhando pela estrada de terra em direção à cidade - reforçam a ideia de que o problema do campo estaria na deficiência da legislação que regula as relações de trabalho. Nessa perspectiva, as "soluções" impostas pela legislação se resumiriam a "ser favelado na cidade ou ser boia-fria no campo" (MONTES CLAROS EM FOCO, 1979, p. 56).

\section{A luta pela terra no Norte de Minas: "entre morrer de fome ou de tiro"}

A dinâmica proporcionada pelo ideal desenvolvimentista acabou por permear todas as relações estabelecidas, causando profundas transformações na vida do homem do campo. No Norte de Minas não foi diferente. As ações do governo - estadual ou federal - para modernizar a economia da região esbarraram nas necessidades dos moradores locais, causando um enorme descompasso entre estes e o poder público. Muitos trabalhadores não conseguiram lidar com essa situação e deixaram o campo, fato que resultou na venda das terras a preços módicos. Outros, ainda, tiveram suas propriedades tomadas por fazendeiros ou empresas que não mediram esforços para isso.

Assim, expulsos de suas terras ou seduzidos pelo discurso do progresso, muitos foram morar nas pequenas cidades e passaram a trabalhar como assalariados nas empresas de reflorestamento, nos perímetros irrigados ou nas grandes fazendas de gado. Era possível perceber e sentir o clima tenso ao ler as páginas policiais dos jornais, ao conversar com os vizinhos que sempre contavam sobre um assassinato, sobre uma cerca que fora aumentada, sobre casas queimadas, trabalhadores demitidos, acidentes com caminhões que transportavam pessoas para o trabalho etc. Parte desse processo pode ser compreendida ao se analisar o conflito de Cachoeirinha, antigo distrito de Varzelândia, na região de Jaíba. Este se tornou o caso mais emblemático da luta pela terra no Norte de Minas. 
Em 1967, 212 famílias de posseiros foram expulsas das terras que ocupavam havia décadas. Consta nos jornais que a retirada dos posseiros foi feita por "12 soldados armados com metralhadoras, acompanhados de vinte e tantos jagunços". O ocorrido ganhou destaque na imprensa regional e nacional (MINAS GERAIS, 1981). Iris dos Santos, esposa de Jader de Paula (líder dos posseiros), era considerada a liderança feminina de Cachoeirinha. Dona Iris revela, em depoimento constante nos autos do processo sobre o despejo dos posseiros, a situação de permanente necessidade a que estavam submetidos, sem alimento para os filhos e para si próprios. Diante da possibilidade de receberem outras terras, mesmo que na mesma região de Jaíba, ressaltou: "[...] Não queremos! Nós morremos de fome ou matado, mas daqui não saímos." (MINAS GERAIS, 1981).

As notícias veiculadas pela mídia a respeito de Cachoeirinha fazem os acontecimentos parecer confusos, embora sua compreensão seja fácil. Entender a dinâmica que envolve essa questão é importante para se compreender a luta pela terra na região. Consta em jornais, e também foi dito por pessoas, que a propaganda sobre terras devolutas feita pelos agentes do Estado de Minas Gerais incentivou muita gente, a partir dos anos iniciais da década de 1960, a seguir em direção à região do Jaíba em busca de seu pedaço de terra, fato que aparece nos depoimentos de posseiros expulsos e está registrado no processo crime que aborda a expulsão. Os autos do processo sobre o despejo dos posseiros de Cachoeirinha, assim como as matérias veiculadas pelos jornais e anexadas ao processo, dão conta da chegada de posseiros a partir de 1963. No entanto, esses documentos não informam sobre os descendentes de escravos ou os nativos que habitavam a região havia mais de 100 anos ou, quando mencionam, o fazem de forma muito discreta. A ideia foi qualificar os posseiros como aventureiros ou interesseiros e, portanto, não merecedores da terra.

A luta dos posseiros de Cachoeirinha para reaverem suas terras se estendeu por quase 20 anos, sendo resolvida pela justiça em 1986, quando os trabalhadores foram legalmente assentados 
em suas antigas terras. No entanto, mesmo depois de assentados, os conflitos entre trabalhadores e fazendeiros permanecem até os dias atuais.

Apesar de Cachoeirinha ter chamado, com mais ênfase, a atenção da imprensa e das autoridades, existiam outros conflitos no Norte de Minas, como mostram os Quadros 2 e 3 a seguir:

Quadro 2 - Conflitos de terra no Norte de Minas. Áreas desapropriadas sem imissão de posse.

\begin{tabular}{|l|l|l|l|l|l|}
\hline \multicolumn{1}{|c|}{ Município } & \multicolumn{1}{|c|}{ Local do conflito } & Famílias & Área (ha) & \multicolumn{1}{c|}{ Data } & Decreto \\
\hline 1) Januária & Faz. Capivara & 67 & 2.850 & $03 / 06 / 1988$ & 96131 \\
\hline 2) Joaquim Felício & Faz. Catoni & 75 & 7.797 & $03 / 06 / 1988$ & 96126 \\
\hline 3) Manga & Faz. Ressaca & & 6.695 & $15 / 01 / 1987$ & 93937 \\
\hline 4) Monte Azul & Faz. Poço da Vovó & 09 & 3.338 & $05 / 07 / 1989$ & 97912 \\
\hline 5) São Romão & Faz. Vargem Grande & & 1.171 & $22 / 07 / 1988$ & 96397 \\
\hline 6) Ubaí & Faz. Pacuí & & 5.290 & $22 / 05 / 1989$ & 97771 \\
\hline 7) Varzelândia & $\begin{array}{l}\text { Várias fazendas - Ca- } \\
\text { choeirinha }\end{array}$ & 100 & 8.423 & $02 / 04 / 1986$ & 92509 \\
\hline \multicolumn{7}{|l|}{} \\
\hline Município & Situação do local do conflito \\
\hline 1) Januária & Pendente na justiça. Classificada como empresa rural. \\
\hline \\
2) Joaquim Felício \\
$\begin{array}{l}\text { Contestado judicialmente. Classificada como empresa rural. Mantém o } \\
\text { conflito. Fazendeiro ganha a liminar, mas a ação do despejo é contestada } \\
\text { pelo STR Bocaiúva, que impede o despejo. }\end{array}$ \\
\hline 3) Manga & Processo adm. suspenso por medida cautelar. Potencial para 120 famílias. \\
\hline 4) Monte Azul & Sem imissão na posse, mantém o conflito. Famílias ocupam a área. \\
\hline 5) São Romão & Contestada na justiça. \\
\hline 6) Ubaí & Contestada na justiça. \\
\hline 7) Varzelândia & Contestada na justiça desde 1986. \\
\hline
\end{tabular}

Fonte: Fórum Popular de Desenvolvimento Regional. Montes Claros, 1993, 44 p.

Quadro 3- Áreas desapropriadas com imissão na posse e em fase de assentamento.

\begin{tabular}{|l|l|l|l|l|l|}
\hline Município & Local do conflito & Famílias pessoas & Área (ha) & Data & Decreto \\
\hline 1) Januária & Faz. Picos & 46 & 9.054 & $21 / 09 / 1989$ & 98153 \\
\hline 2) Montalvânia & Faz. Vaca Preta & & 5.431 & $21 / 09 / 1989$ & 98165 \\
\hline 3) Manga & $\begin{array}{l}\text { Faz. Agrivale e } \\
\text { Mocambinho Ja- } \\
\text { iba I }\end{array}$ & 295 & 20.577 & $22 / 09 / 1986$ & 93302 \\
\hline 4) Manga & $\begin{array}{l}\text { Faz. Manga ou } \\
\text { Japoré }\end{array}$ & 25 & 6.509 & $10 / 08 / 1987$ & 94753 \\
\hline
\end{tabular}




\begin{tabular}{|c|c|c|c|c|c|}
\hline 5) São Romão & $\begin{array}{l}\text { Faz. São João Bo- } \\
\text { queirão }\end{array}$ & 33 & 17.348 & 04/09/1987 & 94840 \\
\hline 6) São Romão & $\begin{array}{l}\text { Faz. Brejo Verde } \\
\text { Logradouro }\end{array}$ & & 3.322 & 05/08/1988 & 96508 \\
\hline 7) São Romão & $\begin{array}{l}\text { Reserva Logra- } \\
\text { douro ou Projeto } \\
\text { Sagarana }\end{array}$ & 120 & 8.000 & 1960 & $\begin{array}{l}\text { Coloniza- } \\
\text { ção Incra }\end{array}$ \\
\hline 8) São Romão & $\begin{array}{l}\text { Faz. Vereda gran- } \\
\text { de }\end{array}$ & 127 & 7.229 & $13 / 10 / 1983$ & 88860 \\
\hline $\begin{array}{l}\text { 9) São Fran- } \\
\text { cisco }\end{array}$ & $\begin{array}{l}\text { Faz. Morrinhos ou } \\
\text { Água Branca }\end{array}$ & 32 & 1.170 & 21/06/1989 & 97856 \\
\hline 10) Varzelândia & Faz. Caitité & 10 & 964 & 03/1987 & Compra \\
\hline 11) Varzelândia & $\begin{array}{l}\text { Faz. Córgão ou } \\
\text { Boa Esperança }\end{array}$ & 33 & 2.420 & 29/08/1988 & 96439 \\
\hline Município & \multicolumn{5}{|l|}{ Situação } \\
\hline 1) Januária & \multicolumn{5}{|c|}{ Imissão na posse sem projeto de assentamento. } \\
\hline 2) Montalvânia & \multicolumn{5}{|c|}{ Imissão na posse em 04/04/1990. } \\
\hline 3) Manga & \multicolumn{5}{|c|}{$\begin{array}{l}\text { Com imissão na posse em 22/09/1987, sem projeto de assentamento. Estima-se } \\
\text { potencial de } 4.100 \text { beneficiários. }\end{array}$} \\
\hline 4) Manga & \multicolumn{5}{|c|}{$\begin{array}{l}\text { Imissão na posse em, 16/03/1988, ainda ocupada pelo proprietário. Potencial } \\
\text { para } 238 \text { beneficiários. }\end{array}$} \\
\hline 5) São Romão & \multicolumn{5}{|c|}{$\begin{array}{l}\text { Imissão na posse em } 28 / 07 / 1988 \text {, mas ocupada por grileiro. Potencial para } \\
506 \text { beneficiários. }\end{array}$} \\
\hline 6) São Romão & \multicolumn{5}{|c|}{ Imissão na posse em 15/04/1989. Potencial para 126 beneficiários. } \\
\hline 7) São Romão & \multicolumn{5}{|c|}{ Sem projeto parcelamento para novos colonos. PROCERA/88 30.000 OIN's. } \\
\hline 8) São Romão & \multicolumn{5}{|c|}{$\begin{array}{l}\text { Imissão na posse em 19/10/1985. } \\
1990 \text { - Projeto parcelamento aprovado, mas parado. Ainda não concretizadas } \\
\text { as reivindicações do projeto de assentamento: } 07 \text { escolas, } 01 \text { posto de saúde, } \\
45 \text { km de estradas, } 07 \text { poços artesianos e divisão da área em } 194 \text { lotes. }\end{array}$} \\
\hline $\begin{array}{l}\text { 9) São Fran- } \\
\text { cisco }\end{array}$ & \multicolumn{5}{|c|}{ Imissão na posse em 05/11/1991. } \\
\hline 10) Varzelândia & \multicolumn{5}{|c|}{ Projeto parcelamento aprovado. } \\
\hline 11) Varzelândia & \multicolumn{5}{|c|}{$\begin{array}{l}\text { Imissão na posse em 14/02/1989, aprovado projeto parceladamente. Potencial } \\
\text { para } 100 \text { famílias. PROCERA/1989. }\end{array}$} \\
\hline
\end{tabular}

Fonte: Fórum Popular de Desenvolvimento Regional. Montes Claros, 1993, 44 p.

Assassinatos e desrespeito aos direitos humanos somam alguns dos ingredientes que compunham essa realidade. Essa situação era constantemente denunciada pelos trabalhadores e suas organizações de classe, como aconteceu no encontro 
promovido pelo Sindicato dos Trabalhadores Rurais de Buritizeiro e publicado pelo Jornal Corrente, de dezembro de 1981 (CORRENTE, 1981), entre os dias 28 e 29 de novembro, que contou com a presença de 80 lavradores da zona rural de Buritizeiro e de delegações de Montes Claros, Unaí, Manga, João Pinheiro, Janaúba e Jequitaí. O objetivo desse encontro foi discutir os problemas que afligiam os trabalhadores da região.

O evento foi organizado de forma que todos os lavradores pudessem expor suas opiniões. Nos dois dias de debate, concluíram que tudo havia piorado e a questão considerada como mais séria referia-se à posse da terra e à luta desigual que os lavradores enfrentavam na justiça contra as "poderosíssimas firmas". Essas últimas, segundo eles, lançavam mão dos mais "escusos recursos para dobrá-los, usando muitas vezes a violência, queimando barracos, espancando colonos, quando se trata de expulsá-los da posse" (CORRENTE, 1981).

Segundo os dados apresentados pela Comissão Pastoral da Terra no ano de 1985, Minas Gerais apresentava 65 áreas de conflitos de terra com grande índice de violência. Foram 50 trabalhadores mortos, 05 feridos e 05 presos. Os conflitos atingiram 21.123 pessoas, em uma área de 100.953 hectares, com um número elevado de ameaças de morte4. Nos primeiros anos da década de 1990, os dados da Comissão Pastoral da Terra dão conta de 86 conflitos na região, conforme apresentado nos quadros acima.

Os conflitos também aconteceram em virtude da desapropriação de comunidades inteiras para a criação dos perímetros irrigados. Em 1984, o Sindicato dos Trabalhadores Rurais de Janaúba convocou os moradores da região para uma assembleia que aconteceria no dia 29 de julho. A finalidade seria debater a situação de 1.000 famílias que moravam à margem esquerda do Rio Gorutuba e que seriam desapropriadas pela Codevasf. As 2.000 famílias que moravam do lado direito já haviam

4 Disponível em: <https://www.cptnacional.org.br/index.php/component/ jdownloads/download/41-conflitos-no-campo-brasil-publicacao/266-conflitosno-campo-brasil-1985>. Acesso em: 4 nov. 2014. 
sido desapropriadas pela mesma Codevasf na década de 1970 . Segundo informa a nota, essas famílias foram jogadas em favelas, a terra foi entregue a fazendeiros e uma pequena parte teria sido reservada para a colonização. Agora, a Codevasf pretendia retirar as famílias restantes. O impasse se deu porque as famílias não aceitaram a "oferta". Essas desapropriações tinham como propósito a continuação da implantação do perímetro irrigado do Gorutuba (PELEJANDO, 1984).

O clima de tensão e os conflitos na região foram constantemente monitorados pelos órgãos do governo federal, principalmente entre os anos de 1975 e 1985, período de maior investimento do poder público na região. Nesse período, existiu um sistema de monitoramento conduzido por órgãos públicos interessados em manter a "paz e tranquilidade", livrando-a das influências "comunistas". Principalmente porque um ambiente conflituoso se colocava contra os objetivos do governo para a localidade, pois afastava possíveis investidores.

Isso pode ser constatado ao verificarmos uma correspondência emitida pelo escritório da Sudene em Montes Claros à Assessoria de Segurança e Informações da Sudene (ASI), que estava sob os cuidados do Coronel João Batista Ramos Lima. Trata-se de um ofício informando sobre a situação de Cachoeirinha. Consta do relatório, qualificado como secreto e confidencial, que "começa a ser esboçado um movimento por parte de elementos reconhecidamente de tendências esquerdistas, no sentido de dificultar a vinda de grandes grupos para a região conhecida como Jaíba dentro de nossa área de atuação" (ARQUIVO PÚBLICO MINEIRO. DOPS. Pasta 1065). Segundo informa o relatório, havia um esforço conjunto entre estado e órgãos federais para a criação de um ambiente propício para investidores nessa região do país, no entanto,

agitações e arbitrariedades [...] faz com que vários empresários interessados em ali adquirir terras para seus projetos, fiquem intranquilos, temendo problemas com relação a posse e uso das terras que por eles venham a ser adquiridas. (ARQUIVO PÚBLICO MINEIRO. DOPS. Pasta 1065). 
O relatório ainda aponta a grande cobertura dada pela TV Globo-MG, em cadeia nacional, veiculando entrevistas com posseiros, nas quais estes haviam afirmado que "soldados da Polícia Militar mineira metralharam crianças, filhos de posseiros" (ARQUIVO PÚBLICO MINEIRO. DOPS. Pasta 1065). Essas denúncias criavam uma imagem negativa para possíveis investidores, o que acabava atrapalhando os planos dos agentes do Estado para a região.

Ao que parece, a Sudene colaborou com o aparelho repressor do governo militar no sentido de mantê-lo informado sobre esses conflitos ocorridos no Norte de Minas e na tentativa de calar essas vozes. Principalmente porque tais conflitos afastavam possíveis investidores, como já foi mencionado. A existência da Assessoria de Segurança e Informações sugere a magnitude dos projetos implantados no local e o compromisso dos agentes envolvidos, fossem estes empresários, órgãos públicos ou privados, em torná-los bem-sucedidos. Essa questão nos leva a inferir que os objetivos dos agentes do Estado para a região se inserem em uma dinâmica maior que vai além de proporcionar um desenvolvimento econômico, mas está centrado também na organização social e espacial.

Ao confrontar a produção historiográfica com as fontes, podemos inferir que os projetos públicos para a região a transformaram em um terreno minado, abrigando inúmeros conflitos. Existem projetos distintos sendo disputados nesse espaço, embora, por muito tempo, somente um deles tenha sido priorizado pela mídia e pela academia. O desenvolvimento e o progresso tão propalados pela classe dirigente local não seguiram o seu curso original. Enquanto agentes do Estado e governos buscaram, por meio dos seus órgãos de ação, abrir frentes de expansão do capital no Norte de Minas, os trabalhadores buscavam manter-se na terra e dela viver. 


\section{Do campo para a cidade: o caminho da mudança?}

Para muitos, deixar o campo nem sempre foi uma opção, mas uma necessidade que se impôs diante de uma situação extrema. Nesse sentido, a cidade passa a ser encarada como a única alternativa, tornando-se a oportunidade de estudo para os filhos e, talvez, sua própria redenção. Essa é uma questão que passa pela compreensão da sociedade em que vivemos e pela compreensão de seus valores hegemônicos. Um desses valores é a educação escolar, já que a importância dispensada à educação enquanto salvadora é reiterada constantemente. Nas relações estabelecidas socialmente, a educação é apresentada como condição para se obter sucesso, é o caminho para uma vida satisfatória, uma vida diferente do que fora outrora.

Um de nossos entrevistados, o Sr. Humberto Leal, que veio da zona rural de Montes Claros, fornece-nos a dimensão desse significado. Em entrevista, perguntamos se ele havia sentido muita diferença quando chegou a Montes Claros. Sua resposta foi longa e muito detalhada, focando-se, sobretudo, nas dificuldades da vida na cidade. Ao fim da questão, concluiu que "se eu tivesse hoje um estudo mais elevado eu seria outra pessoa, né?". Entretanto, Humberto também reconhece a importância de se ter um capital social que, somado à educação escolar, poderia significar melhorias em sua vida: "talvez pela amizade que eu tenho eu tava mais bem colocado, ganhava um pouquinho mais, que aí dava pra me manter." (LEAL, 2009).

Essa concepção de educação como salvadora e redentora está presente na vida das pessoas e torna-se mais forte quando é confrontada com um passado "sofrido". Por isso, é preciso dar aos filhos a oportunidade que lhes foi negada, ou ainda, faz-se necessário seguir um caminho diferente daquele trilhado pelos pais. A educação e o trabalho, como forma de ganhar honestamente o sustento, podem ser entendidos como alguns dos valores hegemônicos de nossa sociedade. Ao se referir à sua vida na zona rural, Humberto ainda disse que a sua permanência na roça o impedia de trabalhar e estudar. A percepção de 
Humberto sobre o seu passado só faz sentido agora, diante das oportunidades perdidas devido ao pouco estudo. É nesse sentido que o hegemônico é vivido e compartilhado em um terreno comum, no qual predominam interesses convergentes e divergentes, assimilações e resistências.

Assim como Humberto, Domingos Lopes Martins, deficiente físico, nascido em Januária, em 1937, também resolveu deixar a roça para aventurar-se na cidade, em busca de dias melhores. Até os 21 anos, Domingos trabalhou no campo. Em fins da década de 1950, deixou a zona rural e se estabeleceu em Manga, onde trabalhou como barbeiro por 30 anos. Em 1988, ficou desempregado e resolveu tentar a sorte em Montes Claros. Sem condições financeiras para comprar ou alugar uma casa, foi viver sob marquises ou em espaços vazios, ficando nessas condições por cinco anos. Em março de 1991, estava vivendo em um lote vago, na rua Melo Viana, no bairro Morrinhos, próximo ao centro da cidade, quando o proprietário pediu que ele desocupasse o lote. Sem trabalho, com a mulher, quatro filhos e um neto de 2 meses, seguiu para o bairro Santa Lúcia, onde conseguiu um lote com a prefeitura. De posse do terreno, Domingos armou sua barraca, mas logo se viu desabrigado, pois um dos funcionários da Secretaria de Ação Social o expulsou do lote para repassar a outra pessoa. Esse caso foi publicado no Jornal do Norte, em 16 de abril de 1991, devido a denúncias dos moradores a um vereador local (JORNAL DO NORTE, 16 abr. 1991).

Foi buscando conter a ida de trabalhadores como Domingos Lopes Martins e Humberto Leal para os grandes centros que o governo federal se viu obrigado a controlar a migração. Para isso, foi criado o programa Cidades de Porte Médio, em fins da década de 1970. Esse programa foi pensado com o objetivo de "conter os dois grandes fluxos migratórios do país, ou seja, do sul para o centro-sul e do norte para o centro-sul" (DIÁRIO DE MONTES CLAROS, 9 out. 1977), em municípios considerados estratégicos e com condições para absorver o fluxo de pessoas que migravam em direção às capitais do centro-sul. Os recursos seriam captados pelo Ministério do Interior por meio do Conselho 
de Desenvolvimento Urbano junto ao BIRD, uma das instituições que formam o Banco Mundial. O Banco Nacional de Habitação e o governo do estado completariam a parceria.

Para a implantação do Programa em Montes Claros, foi firmado um convênio com a prefeitura. O Programa ficaria sob a gerência da Superintendência de Apoio aos Municípios, vinculada à Secretaria de Estado do Planejamento (OLIVEIRA, 2000).

A maioria dos novos moradores na cidade de Montes Claros era composta por habitantes em condições precárias ou sem nenhuma condição financeira, morando em construções deficientes em morros, à beira das rodovias ou em áreas de risco, como se deu com o sr. Domingos. Em um ambiente como esse, a aquisição da casa própria passou a ser o objetivo perseguido por todos aqueles que não dispunham de um teto. Tornouse, portanto, o grande sonho a ser alcançado. Mesmo com a constante e crescente mobilização popular em prol desse objetivo, a questão da moradia nunca foi tratada de forma efetiva pelos governos, levando à constituição de movimentos organizados, como o Movimento de Defesa dos Favelados (MDF), que lutavam e reivindicavam moradia. ${ }^{5}$

No decorrer da década de 1970, em Montes Claros, alguns programas de habitação foram anunciados pelo poder público municipal em parceria com o Banco Nacional de Habitação, mas nunca foram suficientes. A revista Montes Claros em Foco, em agosto de 1979, veiculou uma matéria ressaltando os problemas sociais na cidade. O título foi "As favelas invadem a cidade" (MONTES CLAROS EM FOCO, ago. 1979, p. 42), e a reportagem enfatizava os problemas relacionados ao aumento populacional e à sua implicação direta: o aumento das favelas. A matéria ressaltou ainda que estudos estavam sendo feitos no sentido de viabilizar

5 Esse movimento foi criado na década de 1970, na região de Belém, na grande São Paulo, com os participantes formando pequenos grupos para reflexão e debate. Posteriormente, o grupo passou a contar com a presença de missionários irlandeses, padres e irmãs, apoiados e incentivados pelo bispo local. Ver: <http://www.mdf.org.br/quem-somos/historico.html>. Acesso em: 20 mar. 2015. 
um conjunto habitacional para aqueles moradores, e que o prefeito Antônio Lafetá Rebelo tinha como meta coibir a invasão de locais públicos e o surgimento de favelas nas margens das vias públicas.

Tal proibição certamente está relacionada às muitas ocupações ocorridas em Montes Claros. Nos primeiros anos de 1970, um grupo de pessoas recém-chegadas do campo ocupou uma área vazia localizada na região norte da cidade. A área era considerada de risco, pois ficava debaixo dos fios de alta tensão da Companhia Energética de Minas Gerais (CEMIG). A trajetória de Constantina Pereira da Silva, quando chegou a Montes Claros após deixar a zona rural, é representativa do que inúmeros desses migrantes experimentaram. Constantina foi uma das muitas pessoas que ocuparam essa área vazia e perigosa da cidade. De lá, saíram em 2010, quando a Cemig construiu, em parceria com o governo, um conjunto de apartamentos para as famílias que ali viviam. Ao ser questionada, em entrevista, sobre as ações públicas quando do momento da ocupação da área, ela conta que:

quando tinha assim na base dos cinco anos que eu morava aqui, hoje [2009] já tem 40 anos, naquele tempo teve uma reunião na prefeitura, sobre nós morando aqui. Aí eles falou assim: que ordem que vocês tem, que vocês invadiu a Vila Mauricéia, aquelas áreas lá pra fazer casa?

Aí eu peguei e falei assim... E eu fui a pessoa que todo mundo ficou besta com o que eu respondi, porque todo mundo queria falar isso né, mas não sabia. Aí, eu falei né, e o juiz estava perto né: - Oh, ninguém fez invadir ali por boniteza e querendo enricar não. A gente só invadiu porque nós não tinha terreno pra morar, e nós não tinha salário pra poder comprar um terreno pra pagar a prestação também. Então, o quê que nós tinha que fazer? Os pais de família, cheio de crianças, nós não tinha onde morar, então foi a única coisa que nós temos que fazer foi invadir a área da CEMIG (SILVA, 2009).

A fala de Constantina, quando associada com a matéria da revista Montes Claros em Foco, deixa claro o modo de pensar 
da classe dirigente local sobre essas questões. A noção de que as "favelas" estariam invadindo a cidade indica uma percepção reduzida e muito conveniente sobre os problemas sociais enfrentados pela cidade. Sugere, portanto, que a pobreza ou a favelização não estão associadas ou não têm relação com a organização social da cidade ou com o sistema capitalista, tornando-se apenas um produto da ingerência no campo.

Como a falta de habitação sempre foi um problema negligenciado pelas autoridades, os movimentos populares organizados que lutavam por moradia em Montes Claros foram, aos poucos, ganhando visibilidade. No início dos anos 1980, especificamente em 1984, em consonância com o seu congênere em São Paulo, o MDF já estava organizado e atuando na cidade.

A primeira atuação de que temos registro aconteceu quando da ocupação de uma área pertencente à Companhia de Distrito Industrial de Minas Gerais (CDI), localizada no Distrito Industrial de Montes Claros. Aárea foi ocupada por um grupo de trabalhadores desempregados. Consta que essas terras estavam destinadas à construção de indústrias, mas estavam desocupadas havia vinte anos. Nos primeiros dias de junho de 1984, cerca de 100 famílias se organizaram e ocuparam esse espaço e, em pouco tempo, já haviam plantado suas roças. A organização contou com o apoio da Comissão Pastoral da Terra, do MDF e do Sindicato dos Trabalhadores Rurais de Montes Claros. Os trabalhadores ocuparam a área por cerca de três anos, mas foram retirados em 8 de novembro de 1987. A imprensa noticiou o fim do conflito e a negociação que foi feita com os trabalhadores com a presença da Comissão Pastoral da Terra. Estes seriam indenizados com dinheiro e sementes e auxiliados no replantio das roças (DIÁRIO DE MONTES CLAROS, out. 1987). ${ }^{6}$

Todos os conflitos e embates vividos no Brasil nesse momento contribuíram para que a questão habitacional tivesse novos contornos na cidade, o que significou também o desenvolvimento

6 Não obtivemos mais informações sobre o que teria acontecido com esse grupo de trabalhadores. 
de outros movimentos organizados na região. Quanto ao poder público, quando atuava, o fazia no sentido de dotar de alguma infraestrutura os novos bairros ou legalizar as ocupações.

\section{Considerações finais}

Ao buscar pelos trabalhadores que viviam em Montes Claros e Norte de Minas durante as décadas de 1970 e 1980, foi possível identificar vários pontos de conflitos em curso na região. $O$ caminho para o desenvolvimento se fez à custa da opressão aos trabalhadores, rurais ou urbanos. A luta pela posse e a permanência na terra transformaram-se em um cativeiro, e a possibilidade de mudança visualizada por esses trabalhadores estava na cidade e não no campo.

As situações de conflito e exploração foram evidenciadas pelos agentes das pastorais sociais da Igreja Católica - em especial, pela CPT e pela PO - e por entidades de classe que, mesmo incipientes, foram importantes na organização e na luta dos trabalhadores. Estes, fossem das cidades ou do campo, lutaram pelo cumprimento dos direitos trabalhistas, por moradia e por uma vida decente, gerando conflitos e incomodando os donos do poder, evidenciando que o tão sonhado caminho para o "desenvolvimento" e o "progresso" não poderia ser alcançado sem a inclusão dos trabalhadores. Portanto, a trajetória dos trabalhadores brasileiros foi e segue sendo construída entre um "desenvolvimento" e um "progresso" excludente, que promove exploração, conflitos e tensões, mas também se faz sob o signo da luta e da esperança em um futuro diferente, mais justo e humano.

\section{Referências}

ARQUIVO PÚBLICO MINEIRO. DOPS. Pasta 1065. Busca geral "Gerogino Jorge de Souza". p. 28-30. Disponível em: <http://www. siaapm.cultura.mg.gov.br>. Acesso em: 8 jan. 2015.

AS FAVELAS invadem a cidade. Montes Claros em Foco. Belo Horizonte, ano XII, n. 36, ago. 1979. 
AUGUSTO, Rosely Carlos. Aprender na prática: narrativas e histórias de lideranças camponesas, no sertão, Norte de Minas, nas últimas três décadas. 2011. 375 f. Tese (Doutorado em Educação) - Faculdade de Educação, Universidade Federal de Minas Gerais, Belo Horizonte, 2011.

COMISSÃO PASTORAL DA TERRA. Conflitos de terra no Brasil. 1985. Disponível em: <http://www.cptnacional.org.br/index.php/component/ jdownloads/finish/43/266? ltemid=23>. Acesso em: 4 nov. 2014.

COMISSÃO PASTORAL DA TERRA. História das lutas dos trabalhadores rurais de Minas Gerais. Montes Claros: Comissão Pastoral da Terra, 1984.

COMISSÃO PASTORAL DA TERRA. História das lutas dos trabalhadores rurais de Minas Gerais. Greve no Paraíso. Montes Claros: Comissão Pastoral da Terra, maio 1984. Brochura. 34 p.

CPT DENUNCIA. Vítimas diárias das reflorestadoras. Integração. Jornal das CEBs, CPT e CPO do Norte de Minas Gerais, Montes Claros, ano III, n. 9, jan./fev. 1985.

DIÁRIO DE MONTES CLAROS, Montes Claros, 9 out. 1977.

FÓRUM POPULAR de Desenvolvimento Regional. Montes Claros, 1993. Brochura encadernada, $44 \mathrm{p}$.

INTEGRAÇÃO. Jornal das CEBs, CPT, CPO do Norte de Minas Gerais, Montes Claros, ano II, n. 12, jul./ago. 1985.

JORNAL DO NORTE, Montes Claros, 16 abr. 1991

LAVRADORES discutem reflorestamento. Corrente, Pirapora, ano V, n. 61, dez. 1981.

LOWY, Michel. Walter Benjamin: aviso de incêndio. Uma leitura das teses "Sobre o conceito de história". São Paulo: Boitempo, 2005.

MDF (2015). Movimento de defesa do favelado. Quem somos. Disponível em: <http://www.mdf.org.br/quem-somos/historico.html>. Acesso em: 20 mar. 2015.

MINAS GERAIS. Processo-crime. Vara Criminal de Montes Claros, Montes Claros, 1981. 330 p. p. 68-70. 
OLIVEIRA, Francisco de. Elegia para uma re(li)gião. Sudene, Nordeste, planejamento e conflitos de classe. 5. ed. Rio de Janeiro: Paz e Terra, 1987.

OLIVEIRA, Marcos Fábio Martins. O processo de formação e desenvolvimento de Montes Claros e da Área Mineira da SUDENE; O problema trabalhista: ameaça ou direito? Montes Claros em Foco, Belo Horizonte, ano XII, n. 36, ago. 1979.

PEREIRA, L. M. Em nome da região, a serviço do capital: o regionalismo político norte-mineiro. 2007. 242 f. Tese (Doutorado em História Econômica) - Faculdade de Filosofia, Letras e Ciências Humanas, Universidade de São Paulo, São Paulo, 2007.

PROGRAMA Mineiro de Cidades de Médio Porte. Diário de Montes Claros, Montes Claros, 9 out. 1977. Arquivo particular de Américo Martins Filho.

RODRIGUES, Luciene. Investimento agrícola e o grande Projeto Jaíba. Uma interpretação: 1970-1996. Tese (Doutorado em História Econômica) - Faculdade de Filosofia, Letras e Ciências Humanas, Universidade de São Paulo, São Paulo, 1998.

RODRIGUES. L. et all. Formação social e econômica do Norte de Minas. Montes Claros: Editora Unimontes, 2000.

TRABALHADORES rurais reagem contra a exploração. Integração. Jornal das CEBs, CPT e CPO de Minas Gerais, Montes Claros, ano II, n. 16, jun. 1986.

\section{Entrevistados}

Humberto Leal Rodrigues. Nasceu em Miralta, zona rural de Montes Claros, no ano de 1966. Chegou a Montes Claros no ano de 1988. Trabalha no grupo Coteminas desde 1990. É casado e pai de três filhos. Mora no bairro Nova Morada, região do grande Santos Reis. 
Constantina Pereira da Silva. Nasceu em Passagem Funda, povoado localizado próximo à cidade de Brasília de Minas. Antes de vir para Montes Claros, Constantina morou no Paraná, em São Paulo e em Goiás. Chegou em Montes Claros na década de 1970.

Recebido em abril de 2016. Aprovado em setembro de 2017. 